\title{
Announcement: 2016 Paper of the Year and Honorable Mentions
}

It is with great pleasure to announce the 2016 Paper of the Year and two honorable mentions - of original manuscripts that were accepted for publication in 2016. These awards represent acknowledgement from the Associate Editors and Editor-in-Chief of Abdominal Radiology of outstanding academic scholarship that translates into clinically useful practice. My congratulations to all the authors.

\section{Paper of the Year}

Ehman EC, Behr SC, Umetsu SE, Fidelman N, Yeh BM, Ferrell LD, Hope TA. Rate of observation and interobserver agreement for LI-RADS major features at CT and MRI in 184 pathology proven hepatocellular carcinomas. Abdominal Radiology (2016) 41: 963-969.

University of California San Francisco

Department of Radiology

San Francisco, CA USA

\section{Honorable Mentions}

1. Heijnen LA, Lambregts DMJ, Lahaye MJ. et al. Good and complete responding locally advanced rectal tumors after chemoradiotherapy: where are the residual positive nodes located on restaging MRI? Abdominal Radiology (2016) 41:1245-1252

Nederlands Kanker Instituut Antoni van Leeuwenhoek Ziekenhuis Radiology

Amsterdam, NETHERLANDS

2. Pendse DA, Makanyanga JC, Plumb AA, et al. Diffusion weighted Imaging for evaluating inflammatory activity in Crohn's disease; comparison with histopathology, conventional MRI activity scores, and faecal calprotectin. Abdominal Radiology (2017) 42:115-123.

University College London Hospitals NHS

Foundation Trust

Department of Imaging, UCLH

London, London

UNITED KINGDOM 